\title{
LITERATURE STUDY OF HARVESTING ENERGY WITH RESOURCES RADIO FREQUENCY
}

\author{
${ }^{1}$ Moch Khafid, ${ }^{2}$ Nurhayati Nurhayati \\ ${ }^{1,2}$ Department of Electrical Engineering, Faculty of Engineering, Universitas Negeri Surabaya \\ Email: ${ }^{1}$ mochkhafid@mhs.unesa.ac.id \\ Email:²nurhayati@unesa.ac.id
}

\begin{abstract}
Energy harvesting is a process of harvesting energy from external sources such as solar, heat, wind and electromagnetic waves or radio frequencies. Energy harvesting research needs to be developed because the use of non-renewable energy is increasingly limited. The use of radio frequency (RF) as a source of energy for harvesting is an effort to generate environmentally friendly energy. This is due to the increasing use of telecommunications technology. Various studies have been carried out with the acquisition of RF from various telecommunications signals and broadcast media (AM/FM, TV/DTV, GSM signals, WiFi signals). This study literature aims to know the general description of harvesting energy, especially those originating from radio / RF frequencies. A simple harvesting energy harvesting system consists of an antenna and a voltage rectifier circuit. The antennas used for RF energy harvesting have different designs according to the type of signal captured, including using periodic log antennas, archimedean spiral antennas, patch antennas, dipole patch antennas, and Vivaldi antennas. The energy yield obtained from the energy harvesting process with radiofrequency sources tends to be small in the milliwatt scale (1.17 $\mu \mathrm{W}$ / cm2 - 20VDC) depending on the type of antenna and radio frequency used (0.3 - $27.5 \mathrm{GHz})$ and can be applied to low power electronic devices.
\end{abstract}

Keywords: Energy harvesting, Radiofrequency (RF), Antenna

\section{INTRODUCTION}

Along with the development of the times has triggered technological developments in the field of information and communication, especially wirelessbased communication systems [1]. Wireless communication systems are one of the most important technologies for promoting development and economic and social progress around the world[2]. Telecommunication infrastructure development is increasing everywhere to rural areas and remote places far from urban areas. There are many base transceiver stations (BTS) that are built to cover wireless service coverage.

More than 5 billion new subscribers using wireless cellular network services worldwide were added in 2010 [3]. According to the Wireless World Research Forum, by 2020 as many as 7 trillion wireless devices will serve 7 billion people[4]. Therefore, there are so many signals scattered around us, so that some studies want to use these signals as an environmentally friendly renewable energy source.[5]. Renewable energy that uses the concept of extracting existing or unused energy is usually called energy harvesting.

The application of energy harvesting on a large scale generally uses energy sources that come from wind, thermal, and sunlight, while on a small scale it generally comes from mechanical vibrations and electromagnetic waves or Radio Frequency (RF). The use of RF is more widely used in low-power devices, ranging from measuring intraocular pressure in medical, measuring temperature, as a wireless sensor network[6], as well as low power based IoT device power generation [7]. However, there is also the application of large-scale energy harvesting that is designed using a hybrid system[2]. It is hoped that in the future the energy harvesting process that is around us can replace devices whose resources use batteries because it can damage the environment later.[8].

The process of taking energy from RF is influenced by several factors, including signal strength, the energy converter circuit, and the distance between the transmitter and the receiver, and the type of antenna.[9]. In this case, the antenna type plays an 
important role to get RF with various RF signals which include FM / AM radio signal, TV / DTV signal, cell phone signal to Wi-Fi signal. The type of antenna used in energy harvesting is the Vivaldi antenna[10], large aperture microstrip antenna [11], and Dual-Band Antenna[12].

Energy processes harvesting according to [7]not only focuses on the RF signal obtained and the type of antenna, but conditioning circuits, matching circuits, and storage circuits also play a role in the energy harvesting process to obtain maximum results. The function of the conditioning circuit is to process the signal received by the antenna into a DC signal. The matching circuit is located between the antenna and the conditioning circuit. This is so that the energy captured by the antenna can be processed by the conditioning circuit optimally. Finally, regarding the storage circuit, this series functions to store energy or the yield of the energy harvesting process [3],[13]. Energy storage is the main way to increase power system flexibility and safety. Distributed energy storage is a fast-growing technology in the areas of distribution networks, smart management, renewable energy resources, and smart transportation[14].

Therefore, it is necessary to study the comparison of harvesting energy so that it can know the basic block diagram of harvesting energy, the type of antenna that can be used for harvesting energy, the RF working frequency used for harvesting energy, the amount of energy produced and the application of harvesting energy.

\section{LITERATURE REVIEW}

\subsection{ENERGY SOURCES}

Energy sources are widely available and scattered on this earth with various forms and use. Several studies have been conducted to utilize these energy sources by converting them into other forms of energy, especially electrical energy, both on a small and large scale. These energies include the following: sunlight[15][16], heat energy [17][18], mechanical vibration[19]-[20], and radiofrequency [21][22]. One of the energy sources in a harvesting energy utilization that is interesting to study is the energy source from radiofrequency.

On research [19]the use of a Wireless Sensor Network (WSN) is very appropriate for the security and monitoring of a system process. WSN has used several sources of harvesting energy to reduce its electricity consumption, one of which is piezoelectric[23][24] which can provide 25-50\% efficiency while the Radio Frequency (RF) is $50 \%$
[23][25]. The potential development of WSN with RF as energy replenishment has been carried out by[26] and on research [25]WSN devices use RF Energy Transmitters (ETs) in 2-D and 3-D modeling recharging. The research also shows that the telecommunications industry is growing.

In this modern digitalization era, it encourages the telecommunications industry to build various supporting infrastructure for telecommunications networks. A large number of telecommunication network infrastructures means that there are many radio frequencies scattered around us unconsciously. In general, radio frequencies around us are only used for communication media and broadcasting media. In connection with renewable energy, it has triggered researchers to carry out various studies to utilize radio frequencies around us into electrical energy. The presence of an AM / FM radio signal[21][27], TV / DTV signal [28][29], GSM signals on cell phones [30][31], Wi-Fi signal [32] ,[33], 4G signal[34] up to the latest $5 \mathrm{G}$ signal [22], is evidence of how diverse radio frequencies are used as a medium of communication and broadcasting.

Energy harvesting with energy sources from RF is trying to be applied to low-power electronic devices or devices (IoT devices and wireless sensor networks) because the power produced is still very small. For this reason, many developments are carried out in an effort to maximize the output of energy harvesting from radio frequencies. Starting from the antenna design, the voltage multiplier circuit, to implementing a hybrid system. At a minimum, the output can be comparable to the battery power used in low-power electronic devices. This achievement was made in order to replace batteries as the main source in the future because the waste from batteries can damage the environment[8].

\subsection{ANTENNA}

The antenna is the front-end of a telecommunication system which is an important component whose performance must be developed so that the process of transmitting signals and receiving signals from electromagnetic waves into electricity can be optimal. There are several types of research related to antennas that have been carried out by several studies. One of the results of this research is that it can capture single band radio signals[35][36], dual-band [12][37][38], and multi-band [39]. Until there is the development of further research by designing an antenna that can later be attached to the human body or clothing[40]. With the existence of these studies, it is 
hoped that it can increase efficiency when harvesting energy from radio frequency so that the energy harvesting results are maximum.

Here are some antennas in the study[12] which is used to harvest energy from radiofrequency sources are folded patch antennas and spiral antennas which can harvest at a frequency of $2.4 \mathrm{GHz}$ while the patch antenna type can harvest energy at a frequency of 500$700 \mathrm{MHz}$. On research[37]designed the antenna for the GSM band $940 \mathrm{MHz}$ and GSM band $1800 \mathrm{MHz}$ with the Compact open split Ring resonator type antenna made from Metamaterial. The folded-dipole antenna type was also developed in research[39]for semi-urban environments where there is RF that can be picked up from television (DTV) and telephone (GSM and 3G) signals. Research[40]develop a power harvester ring so that the band has an RF signal receiving antenna. The antenna was developed with a Microstrip type antenna with various materials (Woven Polyester, Kapton, FR4, and Standard interface material) for a frequency of $2.45 \mathrm{GHz}$.

\section{METHODOLOGY}

The work system of the energy harvesting process with a radio frequency (RF) source can be seen in Figure 1[7]

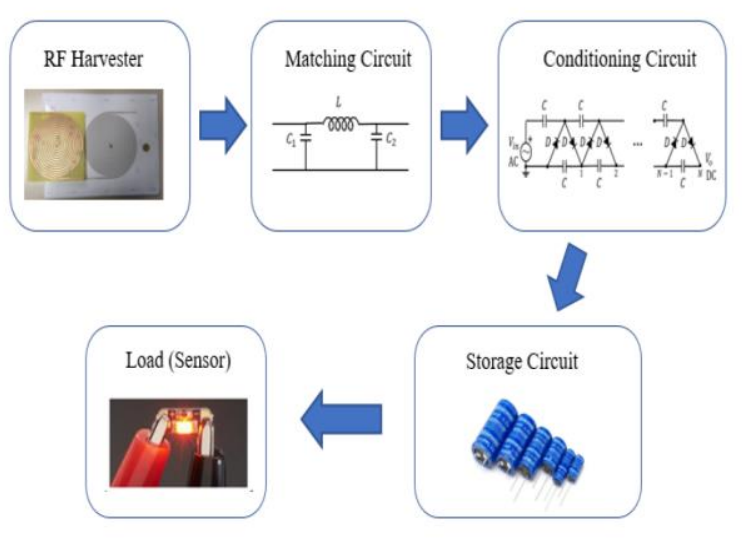

Figure 1. RF energy harvesting system[7]

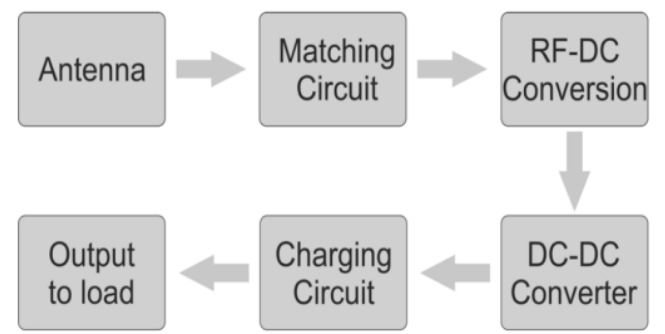

Figure 2. Block diagram of an energy harvesting system[10]
In Figure 1, the RF captured by the RF Harvester, in this case using an archimedean spiral antenna, then the energy is transferred to the conditioning circuit to be converted from sinusoidal or AC waves to DC signals. However, between the RF harvester and the conditioning circuit, a matching circuit is attached to equalize or match the impedance of the RF harvester with the conditioning circuit. When the impedance is equal, the energy captured and converted becomes maximum. After the energy has been successfully converted into DC waves, the energy will be stored in the storage circuit. Furthermore, from the storage circuit, the energy is ready to flow to the load, which is generally a sensor. On research[7]using two types of antennas as a comparison, namely the spiral arch antenna and the patch antenna. The antennas that are used capture more LTE signals with the $800 \mathrm{MHz}$ and $900 \mathrm{MHz}$ bands and for the Conditioning Circuit using HWCW (Half Walf Cockroft Walton).

Harvesting energy research was carried out by [10] using a block diagram that illustrates the process of utilizing $\mathrm{EH}$ with a radio frequency source that goes through 6 stages according to Figure 2.

The principle of energy harvesting in research[10] the same as previous research [7], it's just on research [10]there is the addition of a dc-dc converter process that changes the DC voltage value according to the load. The antenna used in research[10] is a planar antipodal Vivaldi antenna simulated in CST Microwave Studio software.

In research[41] The resulting block diagram can be seen in Figure 3.

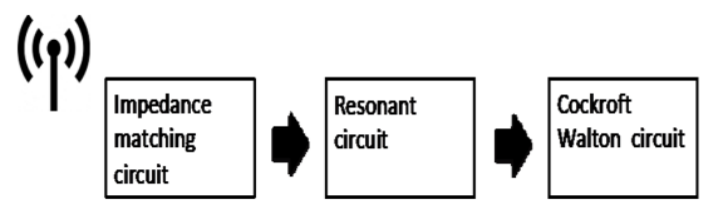

Figure 3. Block diagram of rectenna[41]

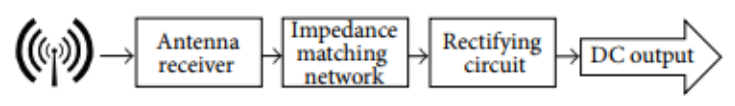

Figure 4. Block diagram of RF energy harvesting system in this study[12]

In Figure 3 it can be seen that the antenna harvests the surrounding RF then the energy is directed towards the impedance matching circuit. Before the AC waveform is converted to DC in the Cockroft Walton circuit, it is energizedpassed a resonant circuit to filter the frequency. Then the energy is directed to the 
Cockroft walton circuit to be converted and at the same time counting the voltage value so that the output reaches the value of the working voltage required by the load. Research[41] later applied to cities. In research[12] according to Figure 4, there are 3 processes to be able to produce DC voltage.

First, the receiver antenna captures the available $\mathrm{RF}$ around the test, to convert the electromagnetic waves into AC electric waves. Impedance matching network here functions to equalize the antenna impedance with the rectifying circuit. Rectifying circuit serves to rectify or convert AC electrical waves to DC so that it can be used on low power devices or devices.

Research[42] The energy harvesting process is very simple as shown in Figure 5.

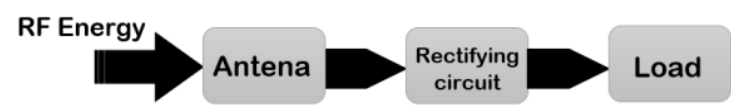

Figure 5. RF electromagnetic energy harvesting system in research[42]
There are 2 devices in processing the captured energy (RF) into DC electricity. The first device is an antenna and the second is a rectifying circuit. The antenna used in this study is a portable quad band ANT-GXH915 antenna that can capture 4 bands, namely $850 \mathrm{MHz}, 900 \mathrm{MHz}, 1.8 \mathrm{GHz}, 1.9 \mathrm{GHz}$. The choice of this antenna is because it is easy to get and can suit research needs[42]. Rectifier circuit in Research[42]using a 5-stage rectifier circuit by installing a $1 \mathrm{nF}$ capacitor component and a Schottky HSMS 2820 diode. The shape of the diode used is in the form of SMD (Surface Mounting Devices) with a minimalist size (3.06 $\mathrm{mm} \times 1.24 \mathrm{~mm}$ ). The experiment in research [07955016] uses LED lights.

On a large scale, research [2]proposes a hybrid energy harvesting system to provide power supply to the BTS (Base Transceiver Station) as backup power if the grid or generator cannot work or experience disruption. In Figure 6, it can be seen that the main energy source can work together with the reserve energy source that comes from solar thermal and RF $\mathrm{EH}$.

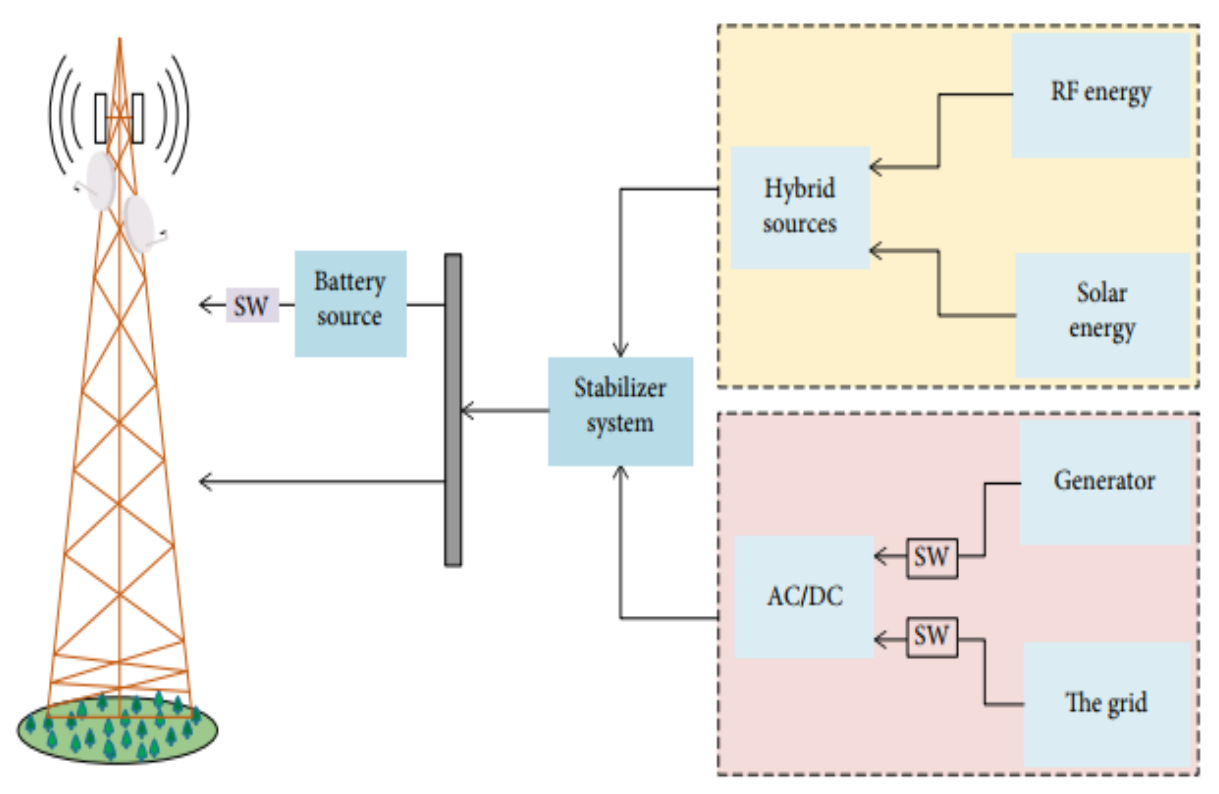

Figure 6. Hybrid energy harvesting system model with solar and Rf Energy Block in the study[2] 


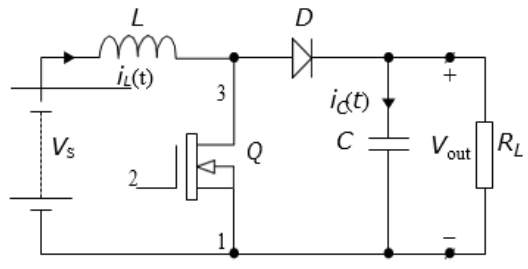

Figure 7. Schematic of a boost converter in research[2]

The components of the hybrid system consisting of solar cells, antenna for RF harvesting, common DC bus, stabilizer system, and spare batteries.

Solar energy consists of a photovoltaic (PV) array. Research[2]applying MPPT (Maximum power point tracking) to adjust the work cycle of the amplifier converter, to achieve high voltage. RF energy consists of an antenna, a matching circuit, and a rectifier circuit. RF is received by the antenna and directed to a matching circuit. The main function of the matching circuit is to increase the input voltage of the rectifier and reduce the energy loss from the antenna to the rectifier. The rectifier functions as a conversion from AC power to DC electricity. Then the electricity from the two results goes to the boost converter to increase its electrical capacity. Then the electricity is directed to the stabilizer system to adjust the voltage to match the voltage on the BTS. The battery system is installed to save power when the hybrid system is at its peak and then used when the power system is not available.
The DC-DC boost converter configuration includes the main input power, inductor, MOSFET transistor, capacitor, diode, and load, as shown in Figure 7 MOSFET transistors $\mathrm{ON}$ and $\mathrm{OFF}$ at certain frequencies and duty cycles. When the MOSFET is ON, the inductor will keep the current flowing and the diode prevents the unnecessary discharge of the capacitor to the source. When the MOSFET is OFF, the capacitor is fully charged by the source and then provides power to the load. So, the boost converter has two working modes, namely the MOSFET transistor ON mode and the TransistorMOSFET OFF mode. Voltage Multiplier on the schematic block diagram research[2] functions to change the source of a low AC input voltage to a higher DC voltage.

\section{RESULTS AND DISCUSSION}

\subsection{RESULTS}

Various available energy sources have been used for human survival. One of them is a source of energy in the form of electromagnetic waves or radiofrequency. The development of telecommunication networks is very fast, so there are so many radio frequencies scattered in the air, especially in urban areas. Therefore, apart from being used as a means of communication, the researchers are interested in utilizing this abundant $\mathrm{RF}$ to be converted into electrical energy. The captured frequency ranges from $0.3-27.5 \mathrm{GHz}$ with various forms of antenna designs. Although its use is only intended for low power devices because the energy output is relatively small, at least in the future it can replace the function of the battery.

Table 1. Comparison Table

\begin{tabular}{|c|c|c|c|c|c|}
\hline Ref & $\begin{array}{c}\text { Antenna } \\
\text { Shape } \\
\end{array}$ & $\begin{array}{c}\text { Frequency of } \\
\text { work } \\
\end{array}$ & Gain & Energy Generated & Application \\
\hline [29], 2013 & $\begin{array}{c}\text { Periodic log } \\
\text { antenna }\end{array}$ & $500-600 \mathrm{MHz}$ & $5-7.3 \mathrm{dBi}$ & $8.99 \mathrm{dBm} / 126.2 \mu \mathrm{W}$ & 16-bit microcontroller \\
\hline [7], 2018 & $\begin{array}{l}\text { Archimedean } \\
\text { spiral }\end{array}$ & $0.3-16 \mathrm{GHz}$ & - & $\begin{array}{c}3,75 \mu \mathrm{W} / \mathrm{cm} 2 \\
\text { (outside laboratory) } \\
1,17 \mu \mathrm{W} / \mathrm{cm} 2 \text { (in } \\
\text { laboratory) } \\
\end{array}$ & $\begin{array}{l}\text { Low power electronic } \\
\text { system }\end{array}$ \\
\hline$[42], 2018$ & $\begin{array}{c}\text { Patch } \\
\text { Antenna }\end{array}$ & $27.5 \mathrm{GHz}$ & - & $90.53 \mathrm{mV}$ & $\begin{array}{l}\text { charge a rechargeable } \\
\text { battery of } 3 \mathrm{~V}, 1 \mathrm{~mA}\end{array}$ \\
\hline$[5], 2016$ & $\begin{array}{c}\text { Dipole Patch } \\
\text { Antenna }\end{array}$ & $915 \mathrm{MHz}$ & - & $7,77 \mathrm{~mW}$ & $\begin{array}{l}\text { rechargeable energy } \\
\text { storage device (battery) }\end{array}$ \\
\hline$[10], 2015$ & $\begin{array}{c}\text { Vivaldi } \\
\text { Antenna } \\
\end{array}$ & $0.8-12 \mathrm{GHz}$ & $6.32 \mathrm{dBi}$ & - & - \\
\hline$[2], 2020$ & - & - & - & 20VDC & $\begin{array}{l}\text { Additional energy for the } \\
\text { Base Transceiver Station } \\
\text { (BTS) power supply }\end{array}$ \\
\hline
\end{tabular}




\subsection{DISCUSSION}

The antenna functions as a signal catcher as well as a converter from electromagnetic waves to AC electric waves. On research[29] use a log periodic antenna and work at a frequency of 500-600 $\mathrm{MHz}$. The energy produced is $8.99 \mathrm{dBm} / 126.2 \mu \mathrm{W}$ with a gain of 5-7.3 $\mathrm{dBi}$. Output on research[29] used for power supply 16 bit microcontroller.

The frequency of $0.3-16 \mathrm{GHz}$ was captured by an archimedean spiral antenna in this study [7]. The energy produced is $3.75 \mu \mathrm{W} / \mathrm{cm} 2$ for testing outside the laboratory, while in the laboratory it produces $1.17 \mu \mathrm{W} / \mathrm{cm} 2$ of energy. The energy generated is applied to low power electronic systems.

A patch antenna is used to capture a signal at a frequency of $27.5 \mathrm{GHz}$ with an unknown gain [42]. The result of energy harvesting is $90.53 \mathrm{mV}$ which is applied to charge a $3 \mathrm{~V}$ battery with a capacity of $1 \mathrm{~mA}$.

The application in research [5] is the same as in research [42], namely the energy is used for energy storage devices, in this case, the battery. However, the energy produced is smaller than the study [42], which is $7.77 \mathrm{~mW}$. The antenna used is in the form of a dipole patch antenna with a working frequency of $915 \mathrm{MHz}$.

The Vivaldi antenna is designed to harvest energy harvesting from RF [10] and the frequency of the captured signal ranges from $0.8-12 \mathrm{GHz}$ with an average gain of $6.32 \mathrm{dBi}$. Experiments were carried out using CST Microwave Studio software.

Subsequent research is a research-based on a hybrid system. However, his research did not explain the shape of the antenna used, the gain, and the working frequency. The energy produced is large enough to measure the energy harvesting from radiofrequency sources, which is $20 \mathrm{VDC}$.

\section{CONCLUSION}

A literature study of radiofrequency harvesting energy has been carried out. Antenna is the initial process of radio frequency harvesting. The forms of antennas used for energy harvesting include periodic $\log$ antennas, archimedean spiral antennas, patch antennas, dipole patch antennas, and Vivaldi antennas. The captured frequency ranges from 0.3 $\mathrm{GHz}$ to $27.5 \mathrm{GHz}$. The energy produced tends to be small on the milliwatt scale, the smallest being 1.17 $\mu \mathrm{W}$ and the largest being $20 \mathrm{VDC}$. With the energy yield that tends to be small, electrical energy can be applied to low-power devices (16-bit microcontrollers and batteries) and can also be used as additional energy to provide power supply to devices that require high power.
The hope in the future is that energy harvesting can produce greater energy, so harvesting can be done using a hybrid system. Harvesting can combine RF energy with energy other than RF, such as: sunlight, geothermal, wind, water, and mechanical vibrations.

\section{Reference}

[1] S. Mekid, A. Qureshi, and U. Baroudi, "Energy Harvesting from Ambient Radio Frequency: Is it Worth it ?," Arab. J. Sci. Eng., vol. 42, no. 7, pp. 2673-2683, 2017, DOI: 10.1007 / s13369016-2308-y.

[2] CV Nguyen, MT Nguyen, TV Quyen, AM Le, and LH Truong, "The Hybrid Solar-RF Energy for Base Transceiver Stations," Wirel. Commun. Mob. Comput., vol. 2020, 2020, DOI: 10.1155 / 2020/8875760.

[3] A. John et al., "Energy Conservation through Site Optimization for Mobile Cellular Systems (Base Transceivers Station Optimization)," vol. 2, no. 1, pp. 26-33, 2012.

[4] K. David, D. Dixit, and N. Jefferies, "2020 Vision: The Wireless World Research Forum looks to the future," IEEE Veh. Technol. Mag., vol. 5, no. 3, pp. 22-29, 2010, doi: 10.1109 / MVT.2010.938595.

[5] Bernacki, R. Gozdur, and N. Salamon, "Experimental study of energy harvesting in the UHF band," J. Phys. Conf. Ser., vol. 709, no. 1, 2016, DOI: 10.1088 / 1742-6596 / 709/1/012009.

[6] ZW Sim and R. Shuttleworth, "Compact Patch Antenna Design for Outdoor Networks," Electromagnetics, vol. 105, pp. 273-294, 2010.

[7] AA Amor, "Design of a Radiofrequency (RF) Energy Harvesting System For Low-Power Sensor Applications at Microwave Bands," POLYTECHNIC UNIVERSITY OF MADRID, 2018.

[8] W. Zhang, C. Xu, W. He, G. Li, and J. Huang, "A review on the management of spent lithium ion batteries and strategy for resource recycling of all components from them," Waste Manag. Res., vol. 36, no. 2, pp. 99-112, 2018, DOI: 10.1177 / $0734242 X 17744655$.

[9] M. CANSIZ, "Radio Frequency Energy Harvesting with Different Antennas and Output Powers," Balk. J. Electr. Comput. Eng., vol. 7, no. 3, pp. 245-249, 2019, DOI: 10.17694 / bajece. 551790 .

[10] J. Schneider, M. Mrnka, J. Gamec, M. Gamcova, and Z. Raida, "Vivaldi antenna for RF energy harvesting," Radioengineering, vol. 25, no. 4, pp. 666-671, 2016, DOI: 10.13164 / re.2016.0666.

[11] I. Savitri, R. Anwar, YS Amrullah, and DA Nurmantris, "Development of large aperture 
microstrip antenna for radio wave energy harvesting," Prog. Electromagn. Res. Lett., vol. 74, no. April, pp. 137-143, 2018, DOI: 10.2528 / PIERL18030305.

[12] A. Bakkali, T. Sogorb, and V. Llario, “A DualBand Antenna for RF Energy Harvesting Systems in Wireless Sensor Networks, "vol. 2016, 2016.

[13] W. Saeed, N. Shoaib, HM Cheema, and MU Khan, "RF Energy Harvesting for Ubiquitous, Zero Power Wireless Sensors," Int. J. Antennas Propag., vol. 2018, 2018, DOI: 10.1155 / 2018/8903139.

[14] X. Li and S. Wang, "A review on energy management, operation control and application methods for grid battery energy storage systems," CSEE J. Power Energy Syst., 2019, DOI: 10.17775 / cseejpes.2019.00160.

[15] V. Raghunathan, A. Kansal, J. Hsu, J. Friedman, and M. Srivastava, "Design considerations for solar energy harvesting wireless embedded systems," 2005 4th Int. Symp. Inf. Process. Sens. Networks, IPSN 2005, vol. 2005, pp. 457-462, 2005, DOI: 10.1109 / IPSN.2005.1440973.

[16] C. Alippi and C. Galperti, "An adaptive system for opimal solar energy harvesting in wireless sensor network nodes," IEEE Trans. Circuits Syst. I Regul. Pap., vol. 55, no. 6, pp. 17421750, 2008,DOI: 10.1109 / TCSI.2008.922023.

[17] I. Stark, "Thermal energy harvesting with thermo life ®," Proc. - BSN 2006 Int. Work. Wearable Implant. Body Sens. Networks, vol. 2006, pp. 19-22, 2006, DOI: 10.1109 / BSN.2006.37.

[18] A. Proto et al., "Thermal energy harvesting on the bodily surfaces of arms and legs through a wearable thermoelectric generator," Sensors (Switzerland), vol. 18, no. 6, 2018, DOI: 10.3390 / s18061927.

[19] JM Gilbert and F. Balouchi, "Comparison of energy harvesting systems for wireless sensor networks," Int. J. Autom. Comput., vol. 5, no. 4, pp. 334-347, 2008, DOI: 10.1007 / s11633008-0334-2.

[20] NS Hudak and GG Amatucci, "Small-scale energy harvesting through thermoelectric, vibration, and radiofrequency power conversion," J. Appl. Phys., vol. 103, no. 10, 2008, DOI: 10.1063 / 1.2918987.

[21] T. Galchev, J. McCullagh, RL Peterson, K. Najafi, and A. Mortazawi, "Energy harvesting of radiofrequency and vibration energy to enable wireless sensor monitoring of civil infrastructure," Nondestruct. Charact. Compos. Mater. Aerosp. Eng. Civ. Infrastructure, Homel. Security. 2011, vol. 7983, no. 734, p. 798314, 2011, DOI: 10.1117 / 12.880174 .
[22] S. El Hassani, H. El Hassani, and N. Boutammachte, "Overview on 5G radio frequency energy harvesting," Adv. Sci. Technol. Eng. Syst., vol. 4, no. 4, pp. 328-346, 2019, DOI: 10.25046 / aj040442.

[23] A. Nechibvute, A. Chawanda, and P. Luhanga, "Piezoelectric Energy Harvesting Devices: An Alternative Energy Source for Wireless Sensors," Smart Mater. Res., vol. 2012, pp. 113, 2012, DOI: 10.1155 / 2012/853481.

[24] S. Roundy, PK Wright, and J. Rabaey, "A study of low-level vibrations as a power source for wireless sensor nodes," Comput. Commun., vol. 26, no. 11, pp. 1131-1144, 2003, DOI: 10.1016 / S0140-3664 (02) 00248-7.

[25] MY Naderi, KR Chowdhury, and S. Basagni, "Wireless Sensor Networks with RF Energy Harvesting: Energy Models and Analysis," pp. 1494-1499, 2015.

[26] R. Gomez Cid-Fuentes, "Enabling the internet of things through energy harvesting: a circuitaware system synthesis-oriented analysis approach," TDX (Dr. en Xarxa's Thesis), no. July, pp. 1-214, 2016, [Online]. Available: https://upcommons.upc.edu/handle/2117/9660 5.

[27] K. Xie, YM Liu, HL Zhang, and LZ Fu, "Harvest the ambient AM broadcast radio energy for wireless sensors," J. Electromagn. Waves Appl., vol. 25, no. 14-15, pp. 20542065, 2011, DOI: 10.1163 / 156939311798072144

[28] C. Mikeka, H. Arai, A. Georgiadis, and A. Collado, "DTV band micropower RF energyharvesting circuit architecture and performance analysis," 2011 IEEE Int. Conf. RFID-Technologies Appl. RFID-FY 2011, no. September, pp. 561-567, 2011, DOI: 10.1109 / RFID-TA.2011.6068601.

[29] RJ Vyas, BB Cook, Y. Kawahara, and MM Tentzeris, "E-WEHP: A batteryless embedded sensor-platform wirelessly powered from ambient digital-TV signals," IEEE Trans. Microw. Theory Tech., vol. 61, no. 6, pp. 2491-2505, 2013, DOI: 10.1109 / TMTT.2013.2258168.

[30] M. Arrawatia, MS Baghini, and G. Kumar, "RF energy harvesting system from cell towers in 900MHz band," 2011 Natl. Conf. Commun. NCC 2011, 2011, DOI: 10.1109 / NCC.2011.5734733.

[31] NM Din, "Design of Rf Energy Harvesting System for," Prog. Electromagn. Res. Vol. 132, 49-69, 2012, vol. 132, no. July, pp. 4969, 2012.

[32] V. Talla, B. Kellogg, B. Ransford, S. Naderiparizi, JR Smith, and S. Gollakota, "Powering the next billion devices with WiFi," Commun. ACM, vol. 60, no. 3, pp. 83-91, 2017, DOI: 10.1145 / 3041059. 
[33] B. Kellogg, A. Parks, S. Gollakota, JR Smith, and D. Wetherall, "Wi-Fi backscatter: Internet connectivity for RF-powered devices," Comput. Commun. Rev., vol. 44, no. 4, pp. 607-618, 2015, DOI: 10.1145 / 2619239.2626319.

[34] MA Tahir, BR Ferrer, and JLM Lastra, "An approach for managing manufacturing assets through radio frequency energy harvesting," Sensors (Switzerland), vol. 19, no. 3, 2019, DOI: 10.3390 / s19030438.

[35] U. Ufklyh, W. Rdwdr, O. Glii, LQS Wrxorxvh, W. Achraf, and R. Alvernh, "Energy Harvesting with 2. $45 \mathrm{GHz}$ Rectenna for urban application, "2018 25th IEEE Int. Conf. Electron. Circuits Syst., vol. 2018, no. December 2018, pp. 345-348, 2019.

[36] J. Masuch, M. Delgado-Restituto, D. Milosevic, and P. Baltus, "Co-integration of an RF energy harvester into a $2.4 \mathrm{GHz}$ transceiver," IEEE J. Solid-State Circuits, vol. 48, no. 7, pp. 1565-1574, 2013, DOI: 10.1109 / JSSC.2013.2253394.

[37] UK Kommuri, I. Rajkumar, PS Chowdhury, and S. Balaji, "Self-sustained RF Energy Harvesting Antenna design for GSM band applications," Int. J. Adv. Res. Sci. Eng. Technol., vol. 5, no. 3, pp. 5378-5385, 2018.

[38] DK Sudeep, "A Dual-Band Microstrip Patch
Antenna for RF Energy Harvesting," vol. 8, no. 06, pp. 31-34, 2019.

[39] M. Piñuela, PD Mitcheson, and S. Lucyszyn, "Ambient RF energy harvesting in urban and semi-urban environments," IEEE Trans. Microw. Theory Tech., vol. 61, no. 7, pp. 2715-2726, 2013, DOI: 10.1109 / TMTT.2013.2262687.

[40] S. Adami et al., "A Flexible 2. 45-GHz Power Harvesting, ”vol. 66, no. 1, pp. 380-395, 2018.

[41] A. Waguaf, R. Alvernhe, L. Fadel, and M. Grzeskowiak, "Energy Harvesting with 2.45 $\mathrm{GHz}$ Rectenna for urban application," 2018 25th IEEE Int. Conf. Electron. Circuits Syst. ICECS 2018, vol. 2018, no. December 2018, pp. 345-348, 2019, DOI: 10.1109 / ICECS.2018.8618025.

[42] N. Mustofa and JE Suseno, "STUDY OF RECTENNA (RECTIFIER ANTENNA) TO CHANGE ELECTROMAGNETIC WAVES INTO A SOURCE," Youngster Phys. J., vol. 5, no. 1, pp. 27-34, 2016.

[43] P. Efthymakis, "A RECTENNA FOR 5G ENERGY HARVESTING," Virginia Commonwealth University, 2018. 